\title{
Studies on cure behavior and rheological characteristics of toughened DGEBA epoxy resin/nanoclay nanocomposites
}

\author{
Sharawan Kumar Shukla ${ }^{1}$, Kavita Srivastava ${ }^{2}$ and Deepak Srivastava ${ }^{1 *}$ \\ ${ }^{1}$ Deartment of Plastic Technology, H. B. Technological Institute, Kanpur - 208002 (U.P.), India. \\ ${ }^{2}$ Department of Chemistry, V.S.S.D. College, Kanpur - 208002 (U.P.), India. \\ *Email: dsri92@gmail.com
}

Epoxy resin is a class of materials widely used in paint and adhesive industries, electrical and electronics, and as matrix in the fabrication of fiber reinforced polymer composites. Potential uses of epoxies are significantly increasing with the addition of small amounts of nanofillers. Nanoclays have been considerably attractive in this area due to their relative low cost, ease of processing and reported thermal, mechanical and barrier property enhancements.

Toughened epoxy resin samples were prepared by blending of diglycidyl ether of bisphenol-A (DGEBA) and cycloalipahtic epoxy resin (CAE) with varying weight ratios $(0-25$ wt.\%) of carboxyl terminated butadiene acrylonitrile $(\mathrm{CTBN})$ copolymer. Influence of 1 - 3 wt.\% MMT on rheological and subsequent cure behavior of prepared epoxy resin was studied using non-isothermal and isothermal rheometry and differential scanning calorimetry (DSC).

Various amounts of MMT were dispersed into prepared epoxy resin using ultra sonication technique at for 24 hours to form a 1, 2 and $3 \mathrm{wt}$ \% MMT/epoxy resin. Stoichiometric amount of curing agent was then added to each epoxy/clay mixture, ultra sonicated for about 5 minutes and degassed for a few minutes. Part of the resin was poured into molds and cured at room temperature for 24 hours followed by 2 hours post curing in a conventional oven set at $80{ }^{\circ} \mathrm{C}$ to form unmodified epoxy and nanocomposites.

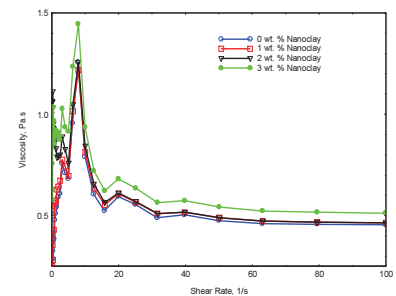

Figure 1: Shear rate dependency on viscosity

Shear rate dependency on viscosity was studied at room temperature on mixtures of toughened epoxy/MMT samples without curing agent and shown in Figure 1.

It is clear from Figure 1 that the interactions between extremely small nanoclay particles and epoxy molecule at shear rates between 0.1 and $5 \mathrm{~s}^{-1}$ were dominated by chemical interactions, while that beyond $5 \mathrm{~s}^{-1}$ was mainly hydrodynamic or shear force due to lack of interaction between clay particles and epoxy molecules.

Figure 2 shows representative curves of viscosity as function of temperature for different MMT loadings and average cure characteristic parameters presented in Table 1.

Table 1: Average cure characteristic parameters

\begin{tabular}{ccccc}
\hline Sample & $\begin{array}{c}\text { Viscosity } \\
\text { at } 30^{\circ} \mathrm{C}, \\
\mu \mathrm{Pa} . \mathrm{s}\end{array}$ & $\begin{array}{c}\text { Lowest } \\
\text { viscosity, } \\
\mu \mathrm{Pa} . \mathrm{s}\end{array}$ & $\begin{array}{c}\text { Temperature } \\
\text { atlowest } \\
\text { viscosity, }{ }^{\circ} \mathrm{C}\end{array}$ & $\begin{array}{c}\text { Gel } \\
\text { Temperatur } \\
{ }^{\circ} \mathrm{C}\end{array}$ \\
\hline \hline $\begin{array}{c}\text { 0 wt. \% } \\
\text { Nanoclay } \\
1 \text { wt. \% }\end{array}$ & $440.3 \pm 6.1$ & $72.9 \pm 15.0$ & $68.7 \pm 1.4$ & $111.8 \pm 4.2$ \\
$\begin{array}{c}\text { Nanoclay } \\
\text { 2 wt. \% }\end{array}$ & $621.1 \pm 18.4$ & $115.5 \pm 34.0$ & $75.8 \pm 2.9$ & $112.0 \pm 3.4$ \\
$\begin{array}{c}\text { Nanoclay } \\
\text { 3 wt. \% }\end{array}$ & $685.1 \pm 19.6$ & $137.7 \pm 19.8$ & $69.3 \pm 1.3$ & $124.1 \pm 1.3$ \\
Nanoclay & $864.7 \pm 26.9$ & $283.4 \pm 14.4$ & $59.2 \pm 1.7$ & $105.7 \pm 2.2$ \\
\hline
\end{tabular}

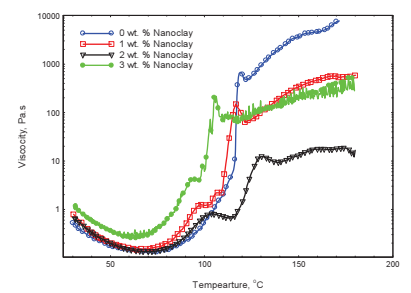

Figure 2: Viscosity as function of temperature

Identical thermograms were obtained with similar characteristic features of the reaction curves during isothermal scans (Figure 3), an indication of lack of MMT influence on the reaction mechanism.

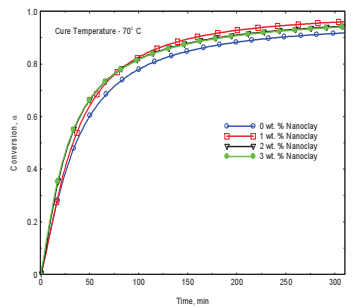

Figure 3: Conversion vs. time for different samples

\section{References}

1. X. Kormann, M. Rees, Y. Thomann, A. Necola, M. Barbezat, R. Thomann, Compos. Sci. Technol. 65 (2005) 2259.

2. M. Alexandre, P. Dubois, Mater. Sci. Eng. 28 (2000) 1. 